\title{
ANALISIS IMPLEMENTASI KEBIJAKAN PUBLIK PENGELOLAAN SAMPAH REFUSED DERIVED FUEL (RDF) DI KABUPATEN CILACAP
}

\author{
Syamsul Auliya Rachman ${ }^{1}$, Muchlis Hamdi ${ }^{2}$, Aries Djaenuri ${ }^{3}$, Ika Sartika ${ }^{4}$ \\ ${ }^{1,2,3,4}$ Institut Pemerintahan Dalam Negeri (IPDN) \\ Email: ar.syamsul@gmail.com
}

\begin{abstract}
Abstrak
Sebagai daerah industri dan jumlah penduduk yang banyak tentunya menimbulkan berbagai macam permasalahan yaitu sampah, pertambahan penduduk akan berbandinglurus dengan miningkatnya jumlah sampah. Kabupaten Cilacap membuat inovasi pengelolaan sampah dengan teknologi Refused Derived Fuel (RDF), yang merubah sampah menjadi bahan bakar alternatif penggati batu bara. Dalam penulisan ini penulis berupaya menganalisisnya dengan desain deskriptif dengan pendekatan kualitatif. Informan penulisan ditentukan dengan purposive sampling. Landasan teori yang digunakan adalah dengan pendekatan teori Van Metter dan Van Horn karena lebih tepat sesuai dengan kondisi implementasi kebijakan pengelolaan sampah. Hasil penulisan ini menunjukan bahwa implementasi kebijakan publik pengelolaan sampah RDF tidak berjalan optimal. Faktor utamanya yaitu pada sumberdaya keuangan dan berbagai pihak yang terlibat justru membuat menjadi tidak optimal dan tidak tepat waktu dikarenakan faktor komunikasi.
\end{abstract}

Kata Kunci: Implementasi Kebijakan Publik, Pengelolaan Sampah RDF, Model Kebijakan.

\section{Abstract}

As an industrial area and a large population, it certainly causes various kinds of problems, namely waste, population growth will be directly proportional to the increase in the amount of waste. Cilacap Regency has made waste management innovations with Refused Derived Fuel (RDF) technology, which turns waste into alternative fuel to replace coal. In this paper the writer tries to analyze it with a descriptive design with a qualitative approach. Writing informants were determined by purposive sampling. The theoretical basis used is the Van Metter and Van Horn theory approach because it is more appropriate to the conditions of implementing the waste management policy. The results of this paper indicate that the implementation of RDF's waste management public policy is not running optimally. The main factor is the financial resources and the various parties involved which actually make it less optimal and not on time due to the communication factor.

Keywords: Public Policy Implementation, RDF Waste Management, Policy Model.

\section{A. PENDAHULUAN}

Pengertian dari Sampah dapat didefenisikan sebagai sisa hasil aktivititas manusia atau merupakan proses dari alamiah yang dapat berbentuk cair dan padat (Kahfi, 2017). Fenomena orang membuang sampah dari kendaraan ataupun membuang sampah di fasilitas publik merupakan salah satu contoh kecil yang menyebabkan terjadinya permasalahan sampah di beberapa daerah di Indonesia. Masalah sebenarnya adalah bahwa sampah rumah 
tangga dan domestic merupakan penyumbang terbesar problematika sampah di wilayah urban (Purnaweni, 2004). Limbah rumah tangga merupakan bahan buangan yang timbul karena adanya kehidupan manusia sehari-hari, baik di perkotaan maupun di pedesaan. Sampah domestik yang kerap disebut limbah rumah tangga dapat berupa limbah padat ataupun limbah cair, dimana limbah hasil buangan dari rumah tangga yang mempunyai bentuk sampah padat dan limbah cair dapat berupa air kotor yang berasal dari aktivitas rumah tangga (PS, 2008).

Di masa depan volume sampah di Indonesia bisa meningkat lima kali lipat jika persoalaan sampah tidak segera di tangani, sehingga diperkirakan satu juta ton tumpukan sampah dalam sehari. Peningkatan sampah tentunya seiring dengan pertumbuhan jumlah penduduk, dengan asumsi semakin bertambah jumlah penduduk maka sampah yang dihasilkan semakin bertambah banyak. Hampir semua negara terutama negara-negara dunia ketiga mengalami permasalahan tentang sampah dan fakta sebaliknya di negara maju seperti China yang telah berhasil mengelola sampah dengan sangat baik seperti dengan bekerjasama dengan pihak swasta (Conner, dkk., 2010).

Pola pembuangan sampah di Indonesia mayoritas dikumpulkan pada suatu tempat penampungan sampah yang disebut Tempat Pembuangan Akhir /TPA (Yogiesti, dkk., 2012). Dampak penurunan kualitas pada lingkungan hidup akan terjadi apabila manajemen sampah di TPA tidak dikelola dengan baik (Nahrudin, 2016). Pada umumnya pengeleloaan secara terbuka atau open dumping menjadi penyebab utama kerusakan pada lingkungan sekitar TPA seperti polusi udara dan air, bau tidak sedap, munculnya kuman penyakit dan lain-lain (Damanhuri, 2010).

Dalam mengelola sampah yang selama ini dilakukan di wilayah perkotaan adalah hanya dengan membakar di ruang terbuka di TPA (Damanhuri, 2006). Metode ini dirasakan tidak efektif dalam mengurangi sampah bahkan hanya akan menimbulkan masalah lainnya yaitu terbentuknya zat-zat kimia berbahaya yang sifatnya polutan seperti karbondioksida, senyawa nitrat dan nitrit maupun gas sulfida yang beracun (Courtemanche \& Levendis, 1998). Sebenarnya negara-negara maju sudah banyak mengembangkan berbagai macam teknologi dalam mengelola sampah seperti teknologi sanitary landfill, incineration, gasification, dan anaerobic digestion (Marshall \& Farahbakhsh, 2013). Penanganan sampah yang masih mengandalkan konsep "kumpul-angkut-buang" semakin memperberat beban pengelolaan sampah (Sahil, dkk., 2016). Keterbatasan dana dalam sektor persampahan membuat penyediaan infrastruktur terkait menjadi sangat tertinggal berbanding volume sampah yang semakin meningkat yang harus di tangani setiap hari oleh pemerintah daerah (Mulyadi, dkk., 2010). Salah satu sumber pembiayaan yang dapat dilakukan adalah melalui 
pemungutan retribusi kebersihan/persampahan yang dikenakan bagi masyarakat. Kesadaran masyarakat dalam berperan serta dalam pengelolaan sampah membuat besaran retribusi yang didapat biasanya masih belum bisa menutupi biaya operasional pengelolaan sampah (Sejati, 2009).

Membahas masalah sampah di Kabupaten Cilacap pengelolaan sampah menjadi salah topik yang selalu dibahas dalam Forum Organisasi Kerja Perangkat Daerah setiap tahunnya. Permasalahannya yaitu sangat minimnya peralatan pendukung, sarana dan sdm yang teribat dalam pengelolaan sampah di kabupaten Cilacap sehingga Pemerintah Kabupaten Cilacap belum mampu memberikan pelayanan pengangkutan sampah yang optimal kepada masyarakat. Berdasarkan data pemkab Cilacap di Dinas Lingkungan Hidup, bahwa volme sampah yang dihasilkan di kabupaten Cilacap sebnayak 400 ton per hari yang terbagi pada 4 TPA yang dikumpulkan setiap hari dengan 34 unit truk sampah yang sebagiannya sudah kurang layak pakai (Cilacap, 2016).

Melihat pada permasalahan pengelolaan sampah yang sampai dengan saat ini belum efektif terselesaikan, maka Pemerintah Daerah Kabupaten Cilacap terus berupaya mencari kebijakan pengelolaan yang tepat untuk mengatasi permasalahan sampah. Oleh karena itu pada tahun 2014 Pemerintah Daerah Kabupaten Cilacap menjalin kerjasama dengan salah satu perusahaan swasta yaitu PT. Solusi Bangun Indonesia (SBI) yang dulunya Semen Holcim Indonesia untuk mengkaji sistem pengelolaan sampah dengan menggunakan teknologi RDF (Refused Derived Fuel) di TPA Tritih Lor Kecamatan Jeruklegi. Sistem pengolahan sampah RDF ini dianggap sebagai metode pengolahan sampah yang tepat untuk wilayah perkotaan (Dong \& Lee, 2009; Kara, 2012). Teknologi RDF yaitu menjadikan sampah di perkotaan menjadi bentuk arang (char) dengan proses pirolisis dan setelah itu dipadatkan sehingga menjadi briket char (Genon \& Brizio, 2008). Berdasarkan hasil penulisaan tentang output produk dari RDF tersebut memiliki nilai kalori yang bisa dijadikan bahan bakar alternitif pengganti batubara (Himawanto, dkk., 2010).

Berdasarkan berbagai uraian permasalahan di atas, pada dasarnya Pemerintah Kabupaten Cilacap sangat berharap bahwa RDF adalah sebuah kebijakan publik yang tepat untuk mengatasi permasalahan pengelolaan sampah, karena model kebijakan pengelolaan sampah dengan sistem dengan sistem open dumping, sanitary landfill dan konsep $3 \mathrm{R}$ (Reuse, Reduse, Recycle) belum secara efektif mengatasi masalah sampah di Kabupaten Cilacap. Implementasi kebijakan pengelolaan sampah dengan teknologi RDF, tampaknya masih menyisakan persoalan dan membutuhkan kajian yang komprehensif terhadap kebijakan 
tersebut, sehingga nantinya kebijakan yang diterapkan oleh Pemerintah Kabupaten Cilacap tidak menimbulkan dampak permasalahan yang lebih besar dalam implementasinya.

Implementasi kebijakan pengelolaan sampah RDF ini hendaknya didesain sedemikian rupa agar tidak sekedar menjadi kebijakan untuk menyelesaikan masalah persampahan saja, akan tetapi justru dapat menimbulkan persoalan publik lainnya ataupun permasalahan hukum lainnya. Pengelolaan sampah dengan teknologi RDF adalah terobosan inovasi, akan tetapi karena sistem pengelolaan sampah ini juga baru pertama di Indonesia diterapkan oleh pemerintah daerah, sehingga harus benar-benar dikaji secara komprehensif dalam segala aspek mempengaruhinya dan para stakeholder yang terlibat dalam implementasi tersebut.

\section{B. METODE}

Penulis menggunakan Qualitative Approach dalam penelitian ini dengan menggunakan metode deskriptif untuk membuat gambaran secara khsusus, terstruktur, akurat dan actual mengenai fenomena yang terjadi pada obyek penelitian (Moleong, 2012; Creswell, 2010). Penelitian kualitatif akan menjelaskan bagaimana proses formulasi kebijakan kerjasama pemerintah swasta dalam proyek pengelolaan sampah di Kabupaten Cilacap dengan menggambarkan serta menganalisis dengan data-data yang ada (Sugiyono, 2010).

\section{HASIL DAN PEMBAHASAN}

Kabupaten Cilacap adalah kabupaten terbesar di Provinsi Jawa Tengah dengan 4 TPA yang masih beroperasi. TPA Tritih Lor di Kecamatan Jeruklegi merupakan TPA terbesar, diperkirakan kapasitasnya akan tercapai pada tahun 2018. Merupakan kebutuhan bagi Pemerintah Kabupaten Cilacap untuk membangun lahan TPA baru, atau untuk melihat beberapa metode alternatif untuk mengelola sampah perkotaan. Salah satu pilihan metode jangka panjang yang berkelanjutan yang diperhatikan oleh Pemerintah Kabupaten Cilacap adalah mengubah sampah perkotaan menjadi Refuse Derived Fuel (RDF), yaitu pemilahan nilai kalori yang tinggi dari sampah yang sudah diproses, yang bisa dipakai sebagai bahan bakar pengganti pada pabrik semen.

Pembangunan pengelolaan sampah RDF pada awalnya yaitu fasilitas RDF yang akan dibangun merupakan kerjasama antara Pemerintah Kabupaten Cilacap dan PT. Holcim Indonesia (swasta pada saat itu dan saat ini sudah berganti menjadi PT. Solusi Bangun Indonesia bagian dari BUMN Semen Indonesia Group). Pada awal rencana kerjasama PT. SBI akan berkontribusi sebanyak 50\% untuk modal pabrik, sedangkan 50\% sisanya merupakan bantuan dari DANIDA melalui program ESP3. Aset yang dibeli oleh DANIDA 
akan dipindahkan ke Pemerintah Kabupaten Cilacap melalui pemerintah pusat yang akan digunakan untuk operasi fasilitas RDF. Tahapan prosesnya adalah ketika fasilitas RDF ini sudah beroperasi, Pemerintah Kabupaten Cilacap akan menyediakan biaya operasional dan pemeliharaan RDF. Secara sederhana konsep ini dapat menghemat modal dan biaya operasional untuk TPA. Badan usaha PT. SBI akan mengoperasikan dan memelihara fasilitas RDF, dan akan menggunakan RDF sebagai bahan pengganti batu bara di kiln pabrik semen milik PT. SBI di Cilacap. Dalam rangka memaksimalkan penggunaan RDF, PT. SBI perlu mengeluarkan biaya tambahan untuk meningkatkan kemampuan pembakaran sistem kilnnya, serta biaya operasional dalam penanganan dan penggunaan RDF namun dalam jangka panjang pemanfaatan RDF akan menghemat biaya pembelian untuk batu bara. Akan tetapi pada implementasinya setelah dirancang biaya pembangunan pengelolaan sampah dengan teknologi RDF ternyata membutuhkan biaya yang cukup besar kurang lebih 80 milyar, sehingga Pemerintah Kabupaten Cilacap berupaya untuk meminta bantuan dari program yang dimiliki Kerajaan Denmark.

Untuk menganalisis implementasi kebijakan ini, penulis memakai kebijakan Van Meter dan Van Horn sebagai model implementasi. Menurut penulis, kedua pakar kebijakan tersebut memberikan suatu pendekatan dasar kebijakan publik dengan beberapa variabel yang membuat kaitan (linked) antara kebijakan dan kinerja (performance) yang cocok yang dikaji dalam kebijakan tersebut (Van Meter \& Van Horn, 1975). Dalam konteks penulisan ini, variabel diterangkan sebagai berikut:

1. Ukuran Dasar dan Tujuan Kebijakan

a. Kerangka Kebijakan dan Peraturan untuk Waste To Energy (WTE)

Pada beberapa tahun terakhir, Pemerintah Indonesia telah mengklarifikasi kebijakan yang positif mendukung pengembangan komersil dari program waste to energy seperti fasilitas RDF sebagai berikut: Peraturan Pengelolalan Sampah, Kebijakan Energi, Komitmen untuk mereduksi emisi gas rumah kaca, dan Rencana Kerja Bali, komitmen untuk perubahan iklim.

b. Pengelolaan Sampah adalah tanggung jawab Pemerintah Pusat, Propinsi dan Daerah

Sebelum desentralisasi, pengelolaan sampah kota menjadi tanggung jawab departemen dan kementerian termasuk Kementerian Pekerjaan Umum, Kementerian Dalam Negeri, Kementerian Kesehatan, Badan Pengkajian Teknologi dan Pengembangan, Badan Pengendalian Dampak Lingkungan, dan Sub Direktorat Pengelolaan Limbah Padat. Keterlibatan beberapa institusi dalam pengelolaan 
sampah menyebabkan tumpang tindihnya tanggung jawab dan lemahnya pelaksanaan dalam penegakan hukum dan peraturan pengelolaan sampah. Desentralisasi pada tahun 1999 telah membawa perubahan di institusi sampah nasional maupun lokal di Indonesia dimana pemerintah pusat berperan sebagai regulator dan pemerintah daerah sebagai pelaku. Pemerintah daerah memiliki lebih banyak tanggung jawab dalam perencanaan dan pelaksanaan pengelolaan sampah di wilayah masing-masing. Selain itu, ada perubahan dalam struktur pengelolaan sampah nasional pada tahun 2002, dengan dikeluarkannya Keputusan Presiden Nomor 2 Tahun 2002. Kementerian Lingkungan Hidup mengambil alih tanggung jawab BAPEDAL yang bertanggung jawab untuk mengendalikan dampak pencemaran lingkungan.

c. Pemerintah Daerah Berinovasi dan Bekerjasama dalam Pengelolaan Sampah Fasilitas RDF yang telah dibangun merupakan kerjasama antara Pemerintah Kabupaten Cilacap, Pemerintah Pusat, Pemerintah Propinsi Jawa Tengah dan NGO DANIDA ESP3 Denmark, dan sebagai pemanfaat hasil atau output dari RDF adalah pabrik semen PT. Solusi Bangun Indonesia. Pemerintah Kabupaten mengadakan lahan, Pemerintah Propinsi Jawa Tengah membantu sebagian infrastruktur pendukung, Pemerintah Pusat melalui Kementrian PUPR membantu membangunkan civil work untuk proyek RDF tersebut. Sedangkan DANIDA ESP3 Denmark akan memberikan hibah aset mesin RDF, dimana aset yang dibeli oleh DANIDA akan dipindahkan ke Pemerintah Kabupaten Cilacap melalui Pemerintah Pusat. Pemerintah Provinsi Jawa Tengah berkomitmen membantu sebagian operasional RDF dan Pemerintah Kabupaten Cilacap berkewajiban mengadakan lahan dan biaya operasional pengankutan sampah ke RDF dan pemeliharaan RDF. PT. SBI selaku mitra kerjasama akan menyediakan SDM, mengoperasikan dan pengankutan hasil RDF. PT. SBI akan menggunakan RDF sebagai bahan pengganti batu bara di kiln pabrik semen, walaupun masih harus berinvestasi pada kiln berupa feeding system. PT. SBI berkomitmen melakukan kerjasama pengelolaan sampah RDF ini karena memiliki harapan adanya efisiensi dan dukungan terhadap pengurangan gas emisi dan waste to energy.

2. Sumber-sumber Kebijakan

a. Sumberdaya Persampahan Kabupaten Cilacap

Potensi Sampah Kabupaten Cilacap: Pemerintah Kabupaten Cilacap mengalami permasalahan persampahan yaitu jumlah sampah yang semakin meningkat setiap 
tahunnya, sedangkan lahan yang digunakan untuk menampung sampah di TPA luasannya semakin berkurang. TPA Jeruklegi memiliki luas $62.723 \mathrm{~m}^{2}$ yang digunakan untuk melayani sampah yang dihasilkan di wilayah Cilacap kota dan wilayah Jeruklegi. Luas daerah dilayani TPA Jeruklegi adalah 41,66 $\mathrm{Km}^{2}$ dari luas total kota Cilacap $67,97 \mathrm{Km}^{2}$. Secara umum, terdapat 2 blok landfill yang saat ini digunakan di TPA Jeruklegi. Satu blok landfill terletak lebih dekat dengan gerbang masuk lokasi TPA. Kondisi Lahan pada Tempat Pembuangan Akhir (TPA) : TPA Jeruklegi dibangun sejak Tahun 1995, dengan luas 6,2 ha yang terdiri dari TPA lama atau pasif seluas 4.9 ha dan TPA baru atau aktif seluas 1.4 ha. Luas area TPA Jeruklegi yang telah digunakan sebesar 23\% atau 6,744 m3 dari total kapasitas $72,800 \mathrm{~m} 3$. Produksi sampah per kapita sebesar 2,064 liter per hari. Sampah yang dibuang ke TPA $277 \mathrm{~m} 3$ per hari atau 139 ton per hari. Dijelaskan lebih lanjut terkait dengan kondisi lahan di TPA.

b. Sumber Daya Manusia

Salah satu hal yang menjadi permasalahan terkait SDM di Kabupaten Cilacap yaitu terjadi pada Dinas Lingkungan Hidup. Dalam Pelaksanaan tugas pokok dan fungsi pada Dinas Lingkungan Hidup Kabupaten Cilacap tentunya memerlukan sumber daya manusia yang memiliki keahlian dan pengetahuan yang memenuhi standar kompetensi dibidang masing-masing, sesuai dengan Peraturan Bupati (PERBUB) Nomor 30 tahun 2018 tentang Perubahan atas Peraturan Bupati Cilacap Nomor 96 Tahun 2016 tentang Kedudukan, Susunan Organisasi, Tugas dan Fungsi Serta Tata Kerja Dinas Lingkungan Hidup Kabupaten Cilacap. Terkait dengan permasalahan SDM yang ada pada Dinas Lingkungan Hidup.

c. Sumber Daya Anggaran RDF

Disadari bahwa implementasi konsep 3R (Reduce Reuse dan Recycle) membutuhkan waktu yang relatif lama agar bisa beroperasi dengan baik dan efisien, sehingga dibuatlah perhitungan dengan mempertimbangkan penanganan sampah eksisting (bussiness as usual, yaitu lebih mengedepankan konsep "kumpulangkut-buang"). Digunakan beberapa asumsi yang sama dengan skenario pencapaian target gerakan nasional (100-0-100). Terdapat beberapa asumsi yang membedakan skenario bussiness as usual dengan skenario 100-0-100. Untuk melaksanakan pengelolaan sampah dengan teknologi RDF membutuhkan anggaran yang tidak sedikit yaitu kurang lebih 80 milyar rupiah. 


\section{Karakter Badan Pelaksana}

a. Dinas Lingkungan Hidup dan TPA Jeruklegi Kabupaten Cilacap

Pemerintah Daerah Kabupaten Cilacap saat ini belum memiliki Jakstrada dimana dokumen tersebut akan dijadikan dasar untuk menjalankan funsi dan tugas utama pengelola persampahan pada Dinas Lingkungan Hidup (DLH). Secara tersirat DLH adalah organisasi perangkat daerah yang memiliki tugas pokok dan fungsi untuk mengelola persampahan di Kabupaten Cilacap. Berkaitan dengan karakteristik pada Dinas Lingkungan Hidup yang memiliki tugas dalam pengelolaan sampah. TPA Jeruklegi merupakan TPA terbesar di kabupaten Cilacap yang dapat menampung722, 55 meter kubik sampah setiap hari dengan luas wilayah sekitar 6,3 ha.

b. DANIDA ESP3 Kerjaan Denmark

Salah satu pihak badan pelaksana dalam terwujudnya pengelolaan sampah dengan teknologi RDF di Kabupaten Cilacap adalah pihak DANIDA ESP3 yang memiliki program dalam bidang lingkungan di Indonesia khususnya Propinsi Jawa Tengah. Kita ketahui bersama bahwa Pemerintah Denmark dan Indonesia terus meningkatkan kerjasama dalam pengelolaan energi bersih. Tujuannya, meningkatkan elektrifikasi dengan tetap menjaga lingkungan. Sehingga hasilnya bisa mengurangi dampak perubahan iklim. Kerjasama antara Denmark dan Indonesia tertuang dalam Environmental Support Programme Phase 3 (ESP3). Dalam pengerjaannya, ESP3 di bawah Danish International Development Agency (DANIDA), bekerja sama dengan tiga Kementerian di Indonesia yakni Lingkungan Hidup dan Kehutanan, Kementerian PPN/Bappenas, dan Kementerian Energi dan Sumber Daya Mineral. Dari dokumen dan data-data yang penulis peroleh bahwa ESP3 ini telah berlangsung sejak 2013 dan akan berakhir pada tahun 2018 dan apabila dilihat dari prosesnya sudah dalam tahap running sudah mencapai 90 persen.

c. Pemerintah Pusat dan Propinsi Jawa Tengah

Pemerintah pusat melalui kementrian PUPR mulai memberikan bantuan dengan membangun sarana dan prasaran pendukung pengolahan sampah sistem RDF di TPA Tritith Lor pada Juli 2017 dan telah selesai proses pembangunannya pada November 2018. Konsep pengelolaan sampah RDF yang ada di Kabupaten Cilacap memiliki kapasitas pengolahan 120 ton sampah/hari dengan menggunakan 
Teknologi Mechanical-Biological Treatment (Pemilahan-Pencacahan-Biodrying). Total nilai bantuan yang diberikan Kementerian PUPR memberikan fasilitas berupa seluruh konstruksi bangunan RDF dengan anggaran sebesar Rp 29 miliar. Pemerintah Provinsi Jawa Tengah memberikan dalam pembangunan sarana penunjang sebesar Rp. 9 milyar serta subsidi bantuan keuangan berupa operasional di 5 tahun pertama operasional RDF. Dengan dukungan pemerintah diharapkan nantinya bisa menurunkan biaya operasional yang harus dikeluarkan oleh Pemerintah Kabupaten Cilacap.

\section{Kondisi Ekonomi, Sosial dan Politik}

a. Tinjauan Secara Regulasi

Sebagai negara yang menjunjung tinggi asas hukum maka dalam setiap pelaksanaan kegiatan yang dilakukan pemerintah atau pemerintah daerah, harus didasarkan pada peraturan perundang-undangan yang berlaku. Terkait dengan pelaksanaan kerjasama daerah ada beberapa aturan yang harus dijadikan dasar rujukan untuk menentukan pola kerjasama yang tepat agar nantinya tidak menjadi masalah dikemudian hari. Karena rencana kerjasama pengolasan sampah RDF antara Pemerintah Kabupaten Cilacap dengan mitra kerjasama nantinya akan menimbulkan biaya yang tentunya akan menjadi beban APBD dan kerjasama ini juga adalah kerjasama yang memanfaatkan aset daerah. Dalam proyek kerjasama pengelolaan sampah di Kabupaten Cilacap.

b. Tinjauan Secara Manfaat Ekonomi

Melihat dari pihak yang memiliki kepentingan sangat besar dalam pengelolaan sampah RDF ini adalah Pemerintah Kabupaten Cilacap, maka dalam mengkaji benefit cost berbeda apabila proyek pngelolaan sampah RDF ini milik swasta. Perbedaan itu baik meliputi prinsip maupun metode, serta komponen yang dianalisis. Kegiatan atau proyek milik pemerintah mempunyai tiga macam manfaat (benefits). Menurut Mangkoesoebroto (1998) tiga manfaat (benefits) adalah: (1) manfaat langsung (direct benefits); (2) manfaat tidak langsung (indirect benefits); (3) manfaat tidak kentara (intangible benefit).

5. Komunikasi dan Sikap antar Badan Pelaksana

Komunikasi dalam organisasi terkadang memiliki permasalahan seperti perbedaan pendapat. Hal ini berhubungan dengan anggota dalam suatu organisasi yang tentu saja memiliki karakteristik, perilaku, pola pikir, dan latar belakang budaya yang berbeda. Berbagai cara dilakukan demi terciptanya tujuan dalam sebuah organisasi. Oleh 
karena itu, komunikasi menjadi sebuah jembatan dalam segala aspek termasuk organisasi untuk mencapai kesamaan makna dan mencapai tujuan yang telah ditetapkan bersama. Berbagai hal dalam berkomunikasi hendaknya dipahami seperti etika, budaya, kebiasaan, adat-istiadat, ruang, waktu, situasi dan lainya akan tetapi hal itulah yang justru kadang-kadang terlupakan. Secara sosiologis, konflik dapat diartikan sebagai suatu proses sosial antara dua orang atau lebih (bisa juga kelompok) di mana salah satu pihak berusaha menyingkirkan pihak lain dengan menghancurkannya atau membuatnya tidak berdaya. Hal-hal yang menyebabkan konflik biasanya dalam sebuah organisasi biasanya karena adanya hubungan saling ketergantungan, adanya perbedaan tujuan, adanya perbedaan persepsi dan adanya permintaan yang tidak terpenuhi. Akibat-akibat dari konflik itu sendiri beragam. Beberapa pendapat (tradisional) menyatakan bahwa konflik hanyalah merupakan gejala abnormal yang mempunyai akibat-akibat negatif sehingga perlu dilenyapkan. Hal ini dapat diartikan bahwa akibat yang ditimbulkan adalah disfungsional. Akan tetapi sebenarnya konflik juga dapat mengakibatkan dampak yang baik dalam hal ini dapat diartikan sebagai dampak fungsional. Konflik merupakan hasil dari kemajemukan sistem organisasi. Lalu jika demikian, apa yang bisa dilakukan untuk menyelesaikan konflik dalam organiasai. Ada beberapa cara untuk melakukan penanganan konflik. Berbicara perihal komunikasi antar badan pelaksana dalam penulisan ini, bahwa komunikasi antar badan pelaksana dapat kita lihat pada awal perencanaan pengelolaan sampah RDF ini, yaitu Pada tahun 2014. Pemerintah Kabupaten Cilacap telah membuat kesepakatan bersama antara Pemerintah Kabupaten Cilacap dengan PT. Holcim Indonesia Tbk yang tertuang dalam Nota Kesepakatan Bersama Nomor: 658.1/89/25/Tahun 2014 dan Nomor: 0558/MoU/LCALCA/HIL/XII/2014 tentang Pengelolaan Sampah di Desa Tritih Lor Kecamatan Jeruklegi Kabupaten Cilacap. Terjalinnya komunikasi antara Pemerintah Daerah Kabupaten Cilacap dengan PT. SBI yang sudah terjalin sejak awal yaitu pada tahun 2014, adalah sebagai upaya untuk sesegara mungkin pemerintah daerah mencari solusi untuk penyelesaian masalah persampahan.

\section{KESIMPULAN}

Pemerintah Kabupaten Cilacap memilih membuat kebijakan publik dalam penanganan masalah sampah, dengan membuat kebijakan pengelolaan sampah dengan teknologi Refused Derieved Fuel (RDF) dengan alasan untuk menghemat anggaran 
dibandingkan dengan membuat TPA baru. Kemampuan sumber daya keuangan dan sumber daya manusia menjadi faktor penting terhadap implementasi kebijakan pengelolaan sampah RDF di Kabupaten Cilacap. Kedua faktor tersebut akan sangat mempengaruhi cepat atau tidaknya terealisasinya kebijakan pengelolaan sampah RDF. Keterbatasan sumber daya keuangan membuat kebijakan pengelolaan sampah RDF di Kabupaten Cilacap melibatkan berbagai pihak dari mulai pemerintah asing, pemerintah pusat dan pemerintah propinsi yang ternyata menjadikan proses implementasi kebijakan berjalan tidak sesuai dengan target perencanaan karena banyak aturan dan regulasi yang dipedomani, karena komunikasi masing-masing badan pelaksana memiliki pemahaman yang berbeda terhadap aturan dan regulasi.

\section{DAFTAR PUSTAKA}

Conner, G., Fisher, B., Hill, J., Hillsman, E., Johnson, B., Kelly, M., ... \& Chandra, C. (2010). Assessing the Potential for Public-Private Partnerships. Woodrow Winson School of Public \& International Affairs of Princeton University.

Courtemanche, B., \& Levendis, Y. A. (1998). A Laboratory Study On The NO, NO2, SO2, $\mathrm{CO}$ and $\mathrm{CO} 2$ Emissions from The Combustion of Pulverized Coal, Municipal Waste Plastics And Tires. Fuel, 77(3), 183-196.

Creswell, J. W. (2010). Research Design Pendekatan Kualitatif, Kuantitatif, Dan Mixed. Yogyakarta: Pustaka Pelajar.

Damanhuri, E. (2006, April). Teknologi dan Pengelolaan Sampah Kota di Indonesia. In Workshop Nasional Biokonversi Limbah (pp. 11-12).

Damanhuri. (2010). Diktat Kuliah: Pengelolaan Sampah. Bandung: ITB.

Dong, T. T., \& Lee, B. K. (2009). Analysis of Potential RDF Resources from Solid Waste and Their Energy Values in the Largest Industrial City of Korea. Waste Management, 29(5), 1725-1731.

Genon, G., \& Brizio, E. (2008). Perspectives and Limits for Cement Kilns as a Destination For RDF. Waste Management, 28(11), 2375-2385.

Himawanto, D. A., Saptoadi, H., Rohmat, T. A., \& Indarto, I. (2010). Pengolahan Sampah Kota Terseleksi Menjadi Refused Derived Fuel Sebagai Bahan Bakar Padat Alternatif. Jurnal Teknik Industri, 11(2), 127-133.

Kahfi, A. (2017). Tinjauan Terhadap Pengelolaan Sampah. Jurisprudentie: Jurusan Ilmu Hukum Fakultas Syariah dan Hukum, 4(1), 12-25.

Kara, M. (2012). Environmental and Economic Advantages Associated with The Use of RDF in Cement Kilns. Resources, Conservation and Recycling, 68, 21-28.

Laporan Akhir Studi Spesifikasi Sampah di Kabupaten Cilacap Tahun 2016.

Mangkoesoebroto, G. (1998). Ekonomi Publik. Yogyakarta: BPFE. 
Marshall, R. E., \& Farahbakhsh, K. (2013). Systems Approaches to Integrated Solid Waste Management in Developing Countries. Waste management, 33(4), 988-1003.

Moleong, L. J. (2012). Metodologi Penelitian Kualitatif. Bandung: Remaja Rosdakarya.

Mulyadi, A., Husein, S., \& Saam, Z. (2010). Perilaku Masyarakat dan Peranserta Pemerintah Daerah dalam Pengelolaan Sampah di Kota Tembilahan. Jurnal Ilmu Lingkungan, 3(02), 147-162.

Nahruddin, Z. (2016). Kemitraan Publik-Privat Dalam Pengelolaan Sampah di TPA Tamangapa Kota Makassar. Government: Jurnal Ilmu Pemerintahan, 9(1), 11-20.

Sahil, J., Al Muhdar, M. H. I., Rohman, F., \& Syamsuri, I. (2016). Sistem Pengelolaan Dan Upaya Penanggulangan Sampah di Kelurahan Dufa-Dufa Kota Ternate. BIOeduKASI, 4(2).

Sejati, K. (2009). Pengolahan Sampah Terpadu. Bandung: Kanisius.

Sugiyono, D. (2010). Metode Penelitian Kuantitatif dan R\&D. Bandung: Alfabeta.

Van Meter, D. S., \& Van Horn, C. E. (1975). The Policy Implementation Process: A Conceptual Framework. Administration \& Society, 6(4), 445-488.

Yogiesti, V., Hariyani, S., \& Sutikno, F. R. (2012). Pengelolaan Sampah Terpadu Berbasis Masyarakat Kota Kediri. Jurnal Tata Kota dan Daerah, 2(2), 95-102.

PS, T. P. (2008). Penanganan dan pengolahan sampah. Penebar Swadaya Grup.

Purnaweni, H. (2004). Implementasi Kebijakan Lingkungan di Indonesia: Hambatandan Tuntutan. Dialogue. 